\title{
"A Bandeira Nacional": vestígios de cooperação evangélica na propaganda nacionalista das ditaduras no Brasil
}

\author{
"The National Flag": vestiges of evangelical cooperation in the nationalist \\ propaganda of the dictatorships in Brazil
}

\section{RESUMO}

\begin{abstract}
O Centro Audio Visual Evangélico - CAVE - foi uma agência interdenominacional de produção de mídia que funcionou no Brasil durante os anos de 1951 a 1971 . O artigo objetiva explorar analiticamente o produto caveano A Bandeira Nacional, composto por áudio (LP) e um conjunto de imagens encontradas nos arquivos do CAVE. A análise, de inspiração genealógica e fundamentação histórico-contextual apresenta nuances da historiografia do CAVE, com ênfase em seus anos finais - momento de produção de A Bandeira Nacional. Duas questões - que se sobrepõem no objeto analisado - motivam o desenvolvimento do texto. A primeira é sobre os motivos de encerramento do CAVE e sua relação com a Bandeira Nacional. Nesse aspecto, a análise indica a confirmação da produção de propaganda nacionalista nos estúdios do CAVE - hipótese anteriormente registrada, mas até então sem nenhuma evidência. A segunda é sobre a participação político-midiática dos evangélicos no espaço público nacional. $\mathrm{A}$ análise da historiografia e produtos do CAVE revela-se como subsídio para compreender a trajetória do intercâmbio político-evangélico no país e o híbrido moral-político-religioso.
\end{abstract}

Palavras-chave: Protestantismo; Ditadura; Fotografia; História da Mídia; Mídia e Religião.

\section{ABSTRACT}

The Centro Audio Visual Evangélico [Evangelical Audio-Visual Centre] - CAVE - was na interdenominational agency for media production that operated in Brazil between 1951 and 1971. This paper intends to analytically explore the production of CAVE entitled The National Flag, formed by an audio piece (LP) and a group of images found out in CAVE archives. This analysis of genealogical inspiration and historical-contextual basis presents nuances of CAVE historiography, especially its last years - the time of the production of The National Flag. Two questions - that superpose themselves to the analyzed object motivate the development of the text. The first one concerns the reasons for the closing of

1. Pesquisadora de Pós-Doutorado Capes/ PNPDI na Escola de Comunicação, Universidade Federal do Rio de Janeiro. Artigo recebido em 09.09.2019 e aceito em 05.12.2019. Contato: prisciladecastro@gmail.com . 
CAVE and their relations to The National Flag. In this matter, the analysis indicates the proof of the production of nationalist propaganda inside the CAVE studios - hypothesis previously written, but so far without evidence. The second one is about the participation, regarding politics and media, of the evangelicals in the national public space. The analysis of CAVE historiography and products presents itself as a resource for the comprehension of the path of the political-evangelical exchange in the country and of this moral-politicalreligious hybrid.

Keywords: Protestantism; Dictatorship; Photography; Media History; Media and Religion.

\section{1- Introdução}

O protestantismo no Brasil viveu intensos conflitos durantes as décadas de 1950 e 1960 (ALVES, 1982; MENDONÇA, 2005). As disputas entre "modernistas" e "fundamentalistas" aconteceu em diferentes níveis, envolvendo uma jovem elite intelectualizada das igrejas tradicionais, por um lado, e dimensões propriamente institucionais, de outro. Eram chamados modernistas especialmente jovens líderes leigos e pastores influenciados por teólogos europeus do século XX². Rubem Alves (1982, p.226) defini o modernismo como "uma atitude frente aos textos sagrados: atitude tipicamente protestante, pois o seu berço foi a Alemanha protestante". Os "fundamentalistas" prevaleceram, promovendo, durante os anos da década de 1960, fechamento de seminários, demissões de professores dessas instituições e intervenções em igrejas locais, com a retirada de pastores considerados "progressistas", comunistas e/ou modernistas - na retórica do expurgo esses termos eram por vezes usados como equivalentes (ALVES, 1982; MENDONÇA, 2005).

O presente artigo apresenta ineditamente fragmentos de uma colaboração protestante/ evangélica para a propaganda nacionalista empreendida durante os chamados "anos de chumbo", durante as ditaduras no Brasil. Trata-se do produto midiático A Bandeira Nacional- um Long Play e um conjunto de imagens produzidos nos estúdios do Centro Audio Visual Evangélico - CAVE. Os materiais foram encontrados durante pesquisa nos arquivos do Centro de Memória de Metodista, CMM, que funciona no Campus de São Bernardo da Universidade Metodista de São Paulo (UMESP).

O CAVE foi uma agência interdenominacional que produziu diferentes tipos de mídia durante os anos entre1951 e 1971. O período de funcionamento da agência atravessou os conflitos internos ao protestantismo no Brasil. $\bigcirc$ material empírico apresentado reforça a leitura histórica da sobreposição do grupo alinhado ao fundamentalismo através, inclusive, de "atos políticos concretos que terminaram por esmagar as vozes dissidentes" (ALVES, 1982, p.36). Rubem Alves (1982) cita, no trecho citado, especificamente a denominação presbiteriana, mas ao construir metodologicamente o tipo ideal Protestantismo da Reta Doutrina, PRD, alerta para o fato de que ele não coincide integralmente com a denominação. Tanto o PRD está presente em outras denominações como outras formas ideais de protestantismos dentro da

\footnotetext{
2 Rubem Alves (1982, p.255) considera que a classificação é "sui generis", "porque teólogos que na Europa seriam considerados conservadores e ortodoxos, como Karl Barth, foram classificados no Brasil como modernistas".
} 
denominação alvo da pesquisa de Alves $^{3}$. Assim, não apenas a Igreja Presbiteriana, mas diversas denominações agiram em nível institucional para 0 silenciamento das discordâncias.

Como referencial histórico-analítico lanço mão especialmente de Rubem Alves (1982) e Antônio Gouvêa Mendonça (2005). A contribuição de Alves para compreensão do contexto e emergência de A Bandeira Nacional ocorre fortemente pelo seu trabalho Protestantismo e Repressão (1982), em que tipifica o protestantismo histórico brasileiro. Mendonça $(2005 ; 2008)$ participa com a caracterização da conjuntura e as mudanças históricas no decorrer do funcionamento do CAVE, demarcando o conflito mencionado no período que o autor designa como "o outro expurgo", compreendendo a repressão institucional de fundamentalistas sobre "modernistas" e "vozes dissidentes" - na expressão alvesiana.

O desenvolvimento do texto se dá no encontro de duas questões motivadoras. A primeira insere-se no contexto amplo da pesquisa sobre o CAVE, explorando seus últimos anos, em busca de desvendar a névoa que paira sobre seu fechamento ${ }^{4}$. A segunda pergunta é pelos modos da participação político-midiática dos evangélicos no espaço público nacional. Ajustando as lentes para enfoques específicos, passamos pelo apoio a posições políticas conservadoras, com fortes elementos nacionalistas e provável influência fascista, e, especialmente, as tensões geradas pela sobreposição políticomidiática-religiosa em diferentes momentos da história do país. A perspectiva metodológica adotada é da genealogia histórica. Portanto, busco traçar um caminho na história para contribuir também com a compreensão do presente. Segue-se, como primeira parte do texto, considerações sobre a metodologia.

\section{Metodologia, métodos e procedimentos de pesquisa}

Os evangélicos no Brasil conquistaram visibilidade midiática a partir da década de 1990. A inserção midiática despertou a atenção de pesquisadores de diferentes áreas do conhecimento. Na virada do milênio, houve uma queda no interesse, embora seja possível rastrear uma produção constante, especialmente nas intersecções evangélicospolítica; e evangélicos-mídia. Apesar das análises da crescente população que se autodeclara pertencente ao segmento religioso nos censos, e da consolidada participação na produção midiática nacional, a forte presença religiosa no pleito presidencial de 2018 intriga observadores do presente. Dos treze candidatos, três são assumidamente evangélicos ${ }^{5}$ e mencionaram questões relacionadas à fé durante a campanha.

Enunciamos acima que uma das questões motivadoras do presente texto é a participação político-midiática dos evangélicos no espaço público nacional, em diferentes períodos da história. Por isso, a genealogia mostra-se como método ou perspectiva adequada para a investigação. Como é próprio da genealogia, trata-se de permitir que a atualidade provoque ao elaborar perguntas; e escutar o ressoar no/do passado na busca

\footnotetext{
${ }^{4} \mathrm{O}$ CAVE foi objeto de pesquisa de doutorado, empreendida entre os anos de 2010 e 2014. Durante esse período, não foi possível encontrar informações seguras sobre o encerramento da organização. $O$ presente texto é, portanto, um desdobramento da Tese, que tem por título Comunicação, Modernidade, Secularização: relações culturais na história e produção do Centro Áudio Visual Evangélico - CAVE (1951 - 1971).

${ }^{5}$ A presença religiosa nas eleições de 2018 foi abordada pela mídia nacional. Para um panorama dos candidatos, suas filiações e posicionamentos religiosos: CHAPOLA, Ricardo. Religião e política: na eleição de 2018 e em outras disputas. Nexo. 01 setembro de 2018. Disponível em: $<$ https: / / www.nexojornal.com.br/expresso/2018/09/01/Religi\%C3\%A3o-e-pol\%C3\%ADtica-naelei\%C3\%A7\%C3\%A3o-de-2018-e-em-outras-disputas>. Acesso em 03 setembro 2018.
} 
por respostas. $\bigcirc$ tempo presente demarca o locus onde as questões são realizadas e para onde elas potencialmente retornam. $O$ artigo, contudo, ocupa-se majoritariamente do passado. Mais precisamente, do CAVE e das condições em que materiais referentes ao produto A Bandeira Nacional estavam guardadas no arquivo.

A adoção da genealogia assume o comprometimento do trabalho do/a pesquisador/a com o seu tempo, libertando-se de um ideal de descrição exata - positiva, portanto -, do passado. Além disso, a genealogia liberta a pesquisa da busca da origem. Por meio dessas duas premissas, também possibilita o desvelo e atenção com vestígios e rastros. Nesse caso específico, em que o presente traz uma questão que parece ressoar algo do passado, Foucault $(1979$, p.15) nos lembra que a genealogia está voltada para a "singularidade dos acontecimentos" e busca:

(...) apreender seu retorno não para traçar a curva lenta de uma evolução, mas para reencontrar as diferentes cenas onde eles desempenharam papéis distintos; e até definir o ponto de sua lacuna, o momento em que eles não aconteceram (Idem, grifo meu).

A proposta, portanto, é pensar retorno, pensar relação. Mas fazê-lo por saltos, busca por continuidades, também por rupturas. Nessa busca, que é ativa,apresento o produto midiático A Bandeira Nacional, encontrado em situações peculiares junto ao arquivo do CAVE.

As informações e fatos apresentados decorrem da pesquisa ampla nos arquivos do CAVE, que envolveu a catalogação dos documentos; a digitalização de parte do acervo; a análise de documentos e imagens encontradas nos arquivos. A análise fundamentou-se nas metodologias de observação direta seguida de descrição; e análise histórico-contextual aplicadas a produtos midiáticos ${ }^{6}$. Em síntese, trata-se de descrever detalhadamente cada parte de cada produto (cada quadro imagético; texto; som; outros elementos, se houver), buscar similaridades e diferenças. A análise é realizada a partir de diferentes dimensões contextuais: tendo a própria organização - o CAVE - como referência; os autores, quando identificados; o momento histórico dos grupos que dirigiam a organização; o contexto político, institucional, cultural e outras.

Uma vez compreendida a relevância do contexto para a metodologia empregada, observa-se a importância dos textos que mencionamos acima como referência histórica de Alves e Mendonça. As tipificações e caracterizações que fazem do grupo e dos períodos históricos oferecem a referência contextual das análises. A ênfase no contexto determinou também o desenvolvimento do texto, que apresenta primeiramente a organização produtora e, posteriormente, o produto alvo do processo.

\section{Produção e história de A Bandeira Nacional: o CAVE}

Os diapositivos de A Bandeira Nacional foram encontrados junto aos documentos organizacionais e materiais de produção do CAVE. Do ponto de vista de sua produção, é correto definir o CAVE como uma agência de mídia. Do ponto de vista jurídico e organizacional, tratava-se de uma associação sem fins lucrativos de que

\footnotetext{
6 A metodologia de análise foi composta a partir de uma série de referências, dentre as quais destacam-se: o texto que abre o livro de Raquel Paiva, "Política: palavra feminina"(Rio de Janeiro: Mauad X, 2008), escrito por Maria Immacolata Vassalo Lopes; o clássico "Pesquisa em Comunicação: formulação de modelo metodológico" (São Paulo: Loyola, 1990), da mesma autora; e a excelente apresentação do campo realizada por Susanna Hornig Priest em "Doing Media Research: an introduction" (2 ed., California: SAGE Publications, 2010) .
} 
participavam igrejas e organizações evangélicas diversas. Em 1966, a organização chegou a ter vinte e oito sócio-membros e protagonizou eventos na área do audiovisual que foram apreciados por representante da Unesco e participantes de outros países da América Latina (BELLOTTI, 2000, p.47).

O sustento do CAVE originava-se no cenário internacional. A organização era financiada majoritariamente por duas organizações norte-americanas: a Radio AudioVisual Education and Mass Communication Comission Overseas, Ravemcco e o Comitê de Cooperação para a América Latina, CCLA. A Ravemcco era o departamento de comunicação do Conselho Nacional de Igrejas em Cristo dos EUA (National Council of Churches in Christ of USA), NCCCUSA. No contexto de "fundamentalistas versus liberais" nos EUA, esse Conselho Nacional representava os cristãos liberais, aproximavase do Evangelho Social e incorporava as agendas do ecumenismo e diálogo interreligioso.

A Ravemcco era fruto de ações voltadas para o então chamado "terceiro mundo", compreendido como localidades assoladas simultaneamente pela pobreza, "a ameaça comunista e as missões fundamentalistas" (BELLOTTI, 2008, p.56). Uma das formas de enfrentar esse contexto era o investimento em produção de conteúdo: a Ravemcco incorporava um projeto de implantação de centros audiovisuais pelo mundo (Bellotti, 2008).

O CAVE surgiu, então, em 1950, "ligado a um projeto de expansão do protestantismo liberal norte-americano e um ideal de cooperação ecumênica do Brasil" (VIEIRA-SOUZA, 20014, p.196). A iniciativa envolveu diferentes organizações evangélicas e foi abrigada pela Confederação Evangélica Brasileira, a CEB. O equipamento inicial pertencia a CEB e a Missão Presbiteriana Central, MPBC, cedeu um missionário para trabalhar na manutenção do material técnico. Também o Presbitério de Rio Claro cedeu um pastor recém reformado para a produção de mídia. A participação de três diferentes organizações evangélicas - uma interdenominacional e duas confessionais, está de acordo com o espírito de cooperação que, de acordo com a periodização de Mendonça (2005), ainda era presente nos primeiros anos da década de 1950.

Mendonça (2005) propõe uma tipificação da história do protestantismo do Brasil, da sua implantação no século 19 até a década de 1980. Segundo o autor, é possível identificar quatro períodos. Primeiramente, a fase de implantação, marcada pelo isolamento social do grupo. Em seguida, entre 1916 e 1952, Mendonça identifica a cooperação interna como a característica forte desse momento, que chegou a ter um movimento unionista7. O terceiro período, de 1952 a 1962, a marca seria "um ensaio de politização" e a chegada no Brasil de "um bando de teologias novas" (MENDONÇA, 2005, p.59). Por fim, de 1962 a 1983, a característica é a "repressão e isolacionismo das igrejas" (Idem, p.61).

O CAVE atravessou três dos quatro períodos propostos por Mendonça. De fato, o surgimento do CAVE apresenta a característica da cooperação. Contudo, a década de 1950 seria marcada também por conflitos - que se refletiram na organização. Para Alves (1982, p.12), uma profunda mudança no comportamento do Protestantismo no Brasil ocorria "a partir de meados da década de [19]50".

O autor decorre sobre isso ao longo do trabalho, mas logo na Nota Preliminar, enuncia como o Protestantismo chega ao Brasil apresentando-se "como uma força renovadora" e desejando "profundas transformações políticas, sociais e econômicas no

${ }^{7} \mathrm{~A}$ expressão "unionismo" expressa um movimento que procurava unificar institucionalmente todas as igrejas protestantes, a exemplo do que havia recentemente em outros países, como Índia e Canadá. $O$ texto de Mendonça $(2005$, p.56) menciona que o projeto fracassou em seus primeiros passos, que foram tentativas de unificar a publicações e a educação teológica. 
país" (ALVES, 1982, p.11). Alves identifica uma reação às "tentativas para se repensar o Protestantismo, nos seus aspectos teológicos, institucionais e sociais" que deflagrou "mecanismos de controle e repressão que terminaram por eliminar totalmente as novas tendências" (Idem, p.12).

Portanto, o CAVE surge como fruto da fase que marcou o auge da cooperação entre organizações e denominações evangélicas, com o protagonismo da CEB. Ao mesmo tempo, nasce no fim dessa fase, vivendo a transição para a seguinte e os conflitos que se instalaram no meio evangélico da época - conforme aponta Alves (1982).

O CAVE consolidou-se no período em que Mendonça (2005, p.59)destaca a "chegada de um bando de teologias novas" aos seminários - que formavam a nova liderança e o clero protestante. Até então a formação da liderança evangélica no país bebia exclusivamente em fontes norte-americanas, classificadas por Alves (1982, p.216) por "missionárias e petistas". Assim, as novidades vinham de teólogos do século XX, especialmente europeus. Essas novas teologias; a conjuntura político-social do país, que exigia respostas aos problemas sociais; e o crescente número de jovens evangélicos que chegavam às universidades geraram o que o autor chama de "ensaio de politização" (MENDONÇA, 2005; p.52). É a época do Setor de Responsabilidade Social da CEB, de Richard Shaul lecionando no Seminário Presbiteriano em Campinas, com as influências do Evangelho Social norte-americano e de teólogos europeus contemporâneos.

Esse é o contexto de florescimento do CAVE e consolidação organizacional, com inauguração da sede própria em Campinas e intensa produção. É o período de produção do diafilme8 "De onde me virá o Socorro?", uma narrativa que "mostrava como, a partir das necessidades de uma senhora que procurou o pastor, toda a igreja se mobilizou para fundar uma creche e fomentar meios consistentes de ação social em sua cidade" (VIEIRA, 2014, s/p). A história aborda diretamente a atuação da igreja em ações sociais estruturais, sugerindo que as igrejas se envolvessem profundamente com suas localidades.

A década de 1960 iniciou em um bom momento para o CAVE, embora os conflitos do contexto protestante apareçam na historiografia e nos produtos (VIEIRASOUZA, 2014) ${ }^{9}$.Não demoraria para que a repressão que caracteriza o período afetasse a organização. O ano de 1962 - que Mendonça (2005) marca como o início da fase marcada pela repressão na história do protestantismo no Brasil - o CAVE vive um conflito que culmina com a saída de um de seus fundadores, Celso Wolf.

A questão que se colocava era a prestação de serviços a terceiros - ou seja, a produção de conteúdos não necessariamente religiosos como forma de contribuir com a sustentabilidade da organização. Contudo, a ideia enfrentou forte resistência e acabou perdendo para a restrição de produção de conteúdo evangelístico. Wolf, que advogava pela captação de recursos através da prestação de serviços, acabou deixando o CAVE em seguida, apesar de ser um dos fundadores e acumular, naquele momento, dez anos de dedicação à organização.

A questão pode parecer pequena para tamanha consequência. Contudo, ela faz sentido no contexto dos conflitos instalados entre fundamentalistas e modernistas e seu desfecho também é coerente com o "silenciamento" mencionado por Alves. Wolf deixou um vazio rapidamente preenchido pelos conservadores. Assim, em 1962 o CAVE inicia

\footnotetext{
8 Diafilme ou filme fixo era a composição de um conjunto de imagens acompanhadas de um script que indicavam o texto que acompanhava cada quadro. As imagens eram diapositivos - fotografias reveladas no tamanho do filme - para serem projetadas em grandes dimensões. O texto também podia ser gravado.

9 O acervo do CAVE é composto por documentos organizacionais diversos: atas, relatórios, correspondências, anotações de comunicação interna, catálogos e outros.
} 
uma nova fase, sob a direção de Américo Ribeiro. Esses anos ainda são bastante produtivos, considerando as datas de produção nos catálogos da organização.

Ribeiro abriu espaço na organização para a participação do coronel Theodoro de Almeida Pupo. Em 1966, o coronel Pupo assumiu a direção da organização e sob sua gestão, o CAVE foi encerrado, com nebulosas explicações sobre as causas de sua falência. Inclusive, não há documentos organizacionais nos arquivos do CMM a partir do ano que a organização passa a ser gerida pelo coronel - assim, nada é possível dizer sobre a saída de Ribeiro e a transição para a gestão de Pupolo.

BELLOTTI (2008) entrevistou fundadores e pessoas que atuaram no CAVE. A historiadora chama a atenção para o silêncio dos entrevistados em relação a detalhes do fechamento da organização. Sem informações precisas a partir das entrevistas, a historiadora analisa o contexto norte-americano e a perda de influência da NCCCUSA:

O fechamento do CAVE no Brasil coincide com o fim da era liberal no protestantismo americano, que perdia poder e influência na cultura americana ao longo dos anos 1960. O envolvimento da NCCCUSA na luta pelos direitos civis provocou uma divisão entre os membros, e a retirada de financiamentos de missões nacionais e internacionais. (BELLOTTI, 2008, p.70)

De fato, os documentos institucionais encontrados apontam para a retirada gradual de financiamento da Ravemcco (que era o departamento de comunicação da NCCCUSA). Contudo, isso por si só não justifica o silêncio e a ausência de informações sobre o encerramento do CAVE.

O primeiro registro da hipótese sobre o fechamento do CAVE está em texto de Leonildo Campos (1997, p.269), que indica o uso das instalações do CAVE para gravar propaganda para a ditadura. Ele afirma que o "envolvimento com o regime militar, interferência de política eclesiástica, acabou desagradando os mantenedores do exterior" e, portanto, isso teria motivado a redução e corte de financiamento (Idem). Tal produção, portanto, teria definido o encerramento do financiamento da Ravemcco que, vale retomar, era ligada aos evangélicos liberais dos Estados Unidos e ao Evangelho Social.

O CAVE abrigou, portanto, as tensões que permearam o protestantismo brasileiro nas décadas de 1950 e 1960 e sua história também revela os rumos que se seguiram, especialmente nos anos de 1970. A organização encarnava um espírito nacionalista, expresso em sua missão de evangelização e educação cristã voltada à nação brasileira (VIEIRA-SOUZA, 2014). Embora apareçam visões contraditórias, mais intensamente nos produtos, em geral a organização figurava a ética social descrita por Rubem Alves (1982) em Protestantismo e Repressão: "converta-se o indivíduo e a sociedade se transformará". A mudança social viria através da conversão pessoal de cada habitante da nação. A educação, nesse sentido, era percebida como uma extensão da conversão e o nacionalismo estava atrelado a um projeto religioso de transformação cada brasileiro/a em um protestante evangélico.

10 Pesquisei informações sobre o coronel Theodoro de Almeida Pupo, com pouco êxito. Em pesquisas na internet, há raras referências ou informações sobre o coronel. Em uma delas, o nome do coronel Pupo pode ser encontrado na edição de 5 de maio de 1970 do Correio da Manhã (Rio de Janeiro). Segundo o jornal, ele havia sido nomeado pelo presidente Emilio Garrastazu Médici como Interventor no Município de Araras, no Estado de São Paulo. Disponível em: <http:// memoria.bn.br/DocReader/Hotpage/HotpageBN.aspx?bib=089842_08\&2pagfis=19869\&url=h ttp:// memoria.bn.br/docreader\#http:// memoria.bn.br/hdb/periodico.aspx> Acesso em 02 set 2019. 


\section{3. "A Bandeira Nacional” e a história de uma pesquisa histórica}

Como A Bandeira Nacional poderia ser mais um vestígio do que uma evidência, fatos sobre a pesquisa nos arquivos contribuem com construção de sentido para o material indicado. A pesquisa nos arquivos do CAVE foi realizada em diferentes momentos durantes o ano de 2012, no contexto de uma pesquisa para doutoramento. A Bandeira Nacional apareceu, primeiramente, em forma de vestígios. Portanto, encontrar A Bandeira Nacional é uma história que pode ser narrada em três etapas: dois vestígios e uma evidência.

O primeiro vestígio. Durante a pesquisa nos arquivos do CAVE, encontrei pela primeira vez a expressão "A Bandeira Nacional" na moldura de eslaides de outros produtos. A moldura estampava as cores verde e amarelo e a inscrição "A Bandeira Nacional". A existência das molduras gerou curiosidade, especialmente porque questões da pesquisa recaíam sobre produtos com mensagem religiosa indireta ou até inexistentell.Havia quatro catálogos de diferentes anos, que foram encontrados junto aos documentos organizacionais e que traziam todos os produtos caveanos disponíveis no ano da publicação. Nenhum deles listava A Bandeira Nacional entre os produtos do CAVE.

Segundo vestígio. Nos últimos dias de pesquisa em arquivo, antes de iniciar a digitalização'2, encontrei um envelope grande fechado. Havia muitas imagens guardadas dentro de envelopes, mas sempre abertos. Ao abrir, deparei-me com outro envelope, menor, manualmente feito de muitas folhas de papéis de seda, grampeado, com a seguinte anotação, escrita à mão: "O1-06-68", "BANDEIRA" [em maiúsculas], "com possibilidade de serem utilizadas". Ao abrir os grampos enferrujados encontrei um conjunto de imagens, fotografias (diapositivos), que faziam referência à bandeira brasileira. As molduras, afinal, haviam sido feitas para abrigar imagens.

O que intriga no modo como esses dois objetos, molduras e imagens, foram armazenados é a relação ocultação versus desvelamento. $\bigcirc$ modo como as imagens estavam guardadas sugeria segredo. Combina com a ausência do produto nos catálogos. Mas o uso indiscriminado das molduras sugere que, ao menos por algum tempo e, talvez, internamente, a existência de A Bandeira Nacional não foi sigilosa. Nesse caso, a ausência nos catálogos poderia ser explicada por outros caminhos. Talvez um produto que não foi vendido nem divulgado para o público geral, os clientes comuns do CAVE. Talvez uma encomenda. Contudo, em algum momento, as imagens mereceram esse tratamento cauteloso, papel seda, vários, grampeados, envelope duplicado.

A evidência. A recuperação do áudio de A Bandeira Nacional ocorreu meses após o fechamento da Tese. Revisitei as imagens do acervo do CAVE em busca de fotos dos diferentes elementos que integram o arquivo no CMM. Além de produtos midiáticos e documentos organizacionais, o acervo também é composto por equipamentos antigos. Com esse equipamento, o CMM expunha uma pequena amostra sobre o desenvolvimento audiovisual no Brasil nas décadas de 1950 a 1980 . A produção de imagens do acervo do CAVE - uma das etapas da pesquisa - abrangeu os elementos caveanos expostos. Em uma das imagens era possível ler o adesivo redondo do centro de um LP que fora colocado em exposição junto ao LP Player - ambos pertenceram ao CAVE. O LP trazia o título "A Bandeira Nacional" junto a logomarca do CAVE. Ali

"Encontrei, de fato, diapositivos com essa característica, curiosamente agrupados como "Série Isca", além de indícios de que o CAVE tenha produzido materiais não-religiosos, como um produto com orientações nutricionais.

${ }^{12}$ Sobre as etapas de pesquisa nos arquivos 
estava a comprovação da existência do produto. A digitalização do áudio permitiu conhecer seu conteúdo. O CAVE apresenta, ao som de uma banda tocando o Hino à Bandeira, a narrativa da lei que regia o uso da bandeira do país. Após os primeiros acordes, uma voz grave e firme anuncia:

O Centro Audio Visual Evangélico apresenta A Bandeira Nacional, primeira parte. Promoção dos Lyons Clubes de Campinas. Elaborado de acordo com a lei de número 5443 de 28 de maio de 1968 [trecho com áudio. Retornam os primeiros acordes do Hino à Bandeira]. Esta [sic] realização só foi possível graças à valiosa colaboração do coronel Sidnei Teixeira Ảlvares, digníssimo comandante da guarnição militar de Campinas.

A Bandeira é um dos símbolos nacionais e foi adotada pelo decreto número quatro de 19 de dezembro de 1889 (...) (CAVE, A Bandeira Nacional)

Ao final da segunda parte, um coro masculino acompanha a banda, cantando o Hino Nacional. Após todo o hino e mais alguns segundos em que prosseguem os instrumentos, o narrador encerra o LP com parte da oração à Bandeira (embora não haja menção à origem do texto):

Bendita sejas Bandeira do Brasil. Bendita sejas pelo teu influxo e pelo teu carinho, que inflamarão todas as almas, condensarão numa só força todas as forças dispersas do território imenso, abafarão as invejas e as rivalidades no seio da família brasileira, e darão coragem aos fracos, tolerância aos fortes, firmeza aos crentes e estímulo aos desanimados. Bendita sejas, para todo o sempre, Bandeira do Brasil. (CAVE, A Bandeira Nacional)

\section{Considerações, evidências e inconclusões}

O artigo apresentou A Bandeira Nacional e sua organização produtora, o CAVE, a partir de duas questões motivadoras que se encontram na análise desse produto. As considerações finais procuram responder a essas perguntas e indicar tanto interdições e limites, quanto caminhos abertos pela análise.

A primeira é a pergunta sobre o fechamento do CAVE. A junção dos vestígios e evidências apresentados nesse texto reforçam a hipótese de Leonildo Campos, de que a organização fechou porque produziu propaganda política em seus estúdios. É fato que, após toda a análise empreendida, pode-se afirmar a produção de propaganda. Contudo, não há evidências suficientes para confirmar uma relação direta entre $A$ Bandeira Nacional e o fechamento da agência.

Os vestígios também nos deixam mais questões do que respostas sobre as imagens. $O$ áudio foi gravado, existe o LP, o título, o dístico do CAVE. Quanto as imagens, não sabemos se chegaram a ser utilizadas. Convém lembrar que a anotação no envelope indicava possibilidade de uso. Há uma correspondência de data - a lei do áudio é de maio de 1968 e as imagens presumivelmente são de junho do mesmo ano.

A segunda pergunta é sobre a participação político-midiática dos evangélicos no espaço público nacional. À essa questão, A Bandeira Nacional desloca questões e abre novas frentes de pesquisa - sempre com o cuidado de compreender a especificidade da produção. $O$ produto integra o quadro de apoio de setores evangélicos aos governos ditatoriais, em seu período mais rigoroso, marcado por perseguições, censura, corpos torturados e desaparecidos. A Bandeira Nacional indica a dimensão e profundidade do envolvimento de evangélicos com a repressão imposta a toda a sociedade naquele momento. Uma questão que se coloca é a relação de colocar em risco o funcionamento 
do CAVE para a produção em parceria com Lyons e Guarnição Militar. A outra hipótese é que o fechamento do CAVE foi planejado. Sem documentação, contudo, essa pesquisa, por ora, fica interditada.

Da perspectiva da mídia, o que A Bandeira Nacional revela ou traz de novidade é um tipo específico de envolvimento evangélico com a política do período: a produção de mídia não apenas pró, com finalidade de atingir o público interno, mas para os propósitos e uso do regime vigente. $\mathrm{Na}$ análise histórico-contextual, o CAVE encarna organizacionalmente a sua duração na história do protestantismo no Brasil (Mendonça, 2005): nasce da cooperação; vive as tensões de um ensaio de politização e abertura; e, por fim, sucumbe em meio a fase de repressão - processos também documentados por Rubem Alves.

Como esboço de contribuições para o presente, assumindo a perspectiva genealógica de salto para investigar o passado e retorno ao contemporâneo, podemos apontar as tendências conservadores do segmento social. E, ainda, a existência do conflito e uma minoria "dissidente" que, em termos atuais, pode-se chamar progressistas e conservadoresis.

Vale anotar ainda a dinâmica ocultação versus desvelamento. No caso de A Bandeira Nacional e do CAVE, é possível identificar a ocultação das imagens e a ausência da referência ao produto nos catálogos; e o sumiço dos documentos organizacionais. Indícios de, no mínimo, dúvidas sobre a exposição do produto. Se o LP permanece exposto, com a logomarca do CAVE impressa, as imagens foram escondidas. Em relação à atualidade, a dúvida parece amenizada. Há uma mudança nas dinâmicas da comunicação, a partir de novas tecnologias e há transformações significativas nas especificidades dos evangélicos como grupo social. $\bigcirc$ grupo conquistou uma parcela significativa da população. Há um desvelamento de suas intenções de hegemonia - e isto é novo. Do apoio indeciso sobre a ocultação ou divulgação, parece haver uma passagem para a imposição, assimilando instrumentos democráticos políticos (além da mídia) para difusão, e ostensiva imposição especialmente de seus valores morais, gerando um híbrido moralpolítico-religioso.

\section{Referências}

ALVES, Rubem. Protestantismo e repressão. São Paulo: Ática, 1982.

BELLOTTI, Karina Kosicki. Uma igreja invisível? Protestantes históricos e meios de comunicação de massa no Brasil (anos 50 a 80). Monografia (Curso de História). Campinas: Universidade de Campinas, 2000.

BELLOTTI, Karina Kosicki. "Delas é o reino dos céus": mídia evangélica infantil na cultura pós-moderna do Brasil (1950 a 2000). Tese (Doutorado em História) - Curso de História, Universidade de Campinas, 2008.

CAMPOS, Leonildo Silveira de. Teatro, Templo e Mercado: organização e marketing de um empreendimento neopentecostal. Petrópolis: São Paulo: São Bernardo do Campo: Vozes; Simpósio Editora; UMESP, 1997.

13 Como referência para continuidades, vale anotar o trabalho de Magali do Nascimento Cunha, "Do púlpito às mídias sociais" (Curitiba: Editora Prisma, 2017), que expressa esse conflito como "pêndulo histórico entre conservadores e progressistas". 
CAVE. A Bandeira Nacional. Campinas: CAVE. s/d. LP

FOUCAULT, Michel. Microfísica do poder. Trad Roberto Machado. Rio de Janeiro: Edições Graal, 1979.

MENDONÇA, Antonio Gouvêa. O protestantismo no Brasil e suas encruzilhadas. REVISTA USP, n.67. São Paulo, setembro/novembro 2005, p. 48-67.

VIEIRA, Priscila. "De onde me virá o socorro?" - Sobre as imagens do blog Dignidade! In Portal Ultimato. 13 maio 2014. Disponível em: <http: / / ultimato.com.br/ sites/ dignidade/ 2014/ 03/13/ de-onde-me-vira-o-socorro-sobreas-imagens-do-blog-dignidade/\#comments > Acesso em 30 maio 2014.

VIEIRA-SOUZA, Priscila. Comunicação, Modernidade, Religião: relações culturais na história e produção do Centro Áudio Visual Evangélico - CAVE (1951 - 1971). Tese. Universidade Federal do Rio de Janeiro (Programa de Pós-Graduação em Comunicação e Cultural). Rio de Janeiro, 2014. 358 p. 